\title{
Time response of a landslide to meteorological events
}

\author{
G. Lollino, M. Arattano, P. Allasia, and D. Giordan \\ CNR-IRPI, Strada delle Cacce 73, 10135 Torino, Italy
}

Received: 26 July 2005 - Revised: 16 January 2006 - Accepted: 16 January 2006 - Published: 15 March 2006

Part of Special Issue "Documentation and monitoring of landslides and debris flows for mathematical modelling and design of mitigation measures"

\begin{abstract}
A landslide affecting two small villages located on the Northwestern Italian Apennines has been investigated since the year 2000 through the use of different equipment. A complex monitoring system has been installed in the area. The system includes several inclinometers, piezometers and a raingauge. An Automatic Inclinometric System (AIS) has been also installed that automatically performs measurements, twice a day, along the entire length of a pipe that is $45 \mathrm{~m}$ deep. This monitoring system has been set up to identify a methodology that allowed to deal with landslides, trying to predict their behaviour beforehand for warning purposes. Previous researches carried out in the same area for a period of about 7 months, in the year 2000, have allowed to identify a correlation between deep slope movements and rainfalls. In particular, it has been possible to determine the time lag needed for a rainfall peak to produce a corresponding peak of the landslide movements; this time lag was of 9 days. This result was possible because the AIS allows to obtain, as mentioned, daily inclinometric measurements that can be correlated with the recorded rainfalls. In the present report we have extended the analysis of the correlation between deep slope movements and rainfalls to a greater period of observation ( 2 years) to verify over this period the consistency of the time lag mentioned above. The time lag previously found has been confirmed. We have also examined the possibility to extend to the entire landslide body the correlation that has been found locally, analyzing the results of the remaining inclinometric tubes with traditional reading installed on the landslide and comparing them with the results of the AIS. The output of the tubes equipped with piezometric cells has also been analyzed. The relations existing among rainfalls, ground water level oscillations and the related slope movements have been explored.
\end{abstract}

Correspondence to: G. Lollino

(g.lollino@irpi.to.cnr.it)

\section{Introduction}

Montaldo and Aie di Cosola (Cabella Ligure, Alessandria, Piedmont Region) are two small hamlets located at about $1000 \mathrm{~m}$ a.s.l. in the mountain area of the Apennines (Fig. 1). The two hamlets are located over a wide (about $2 \mathrm{~km}^{2}$ ) and thick landslide body consisting of a chaotic mixture of materials derived from local formations intermixed with fines (Fig. 1). The constitution of the superficial landslide body was reconstructed using borehole logs. In particular, this complex body has a thickness ranging from few meters in the upper part of the village to $36 \mathrm{~m}$ in the southern lower part. The upper part of the superficial landslide body is constituted by eterometric blocks of limestone and claystone in a silty sand. Clay layers with claystone clasts are present in the lower part of the complex. For a more detailed description of the geologic framework, the structural setting, the nature of the movements and historical records of past collapse events see Lollino et al. (2002). The yearly average rainfall of the area is $1150 \mathrm{~mm}$. The seasonal rainfalls show a peak in Autumn: the months of October and November display the maximum of the monthly average rainfall $(154 \mathrm{~mm}$ and $153 \mathrm{~mm}$, respectively). The minimum monthly average rainfall belongs to the month of July $(58 \mathrm{~mm})$.

An Automatic Inclinometric System (AIS) was installed on the landslide in 2000 (Lollino et al., 2002). The AIS is an inclinometer apparatus designed to be operated by remote control (Lollino, 1992). After the repeated and prolonged rainfalls occurred in October and November 2000, the AIS measured significant movements and allowed to locate a sliding surface at a depth of about $13 \mathrm{~m}$ at the level of a sandysilty layer with some clay lenses inside. The largest return period of the October/November 2000 precipitation was the return period of the rainfalls of 5 consecutive days and it was of 3.5 years.

The movements measurements performed through the AIS in the period September 2000-March 2001 revealed a good

Published by Copernicus GmbH on behalf of the European Geosciences Union. 


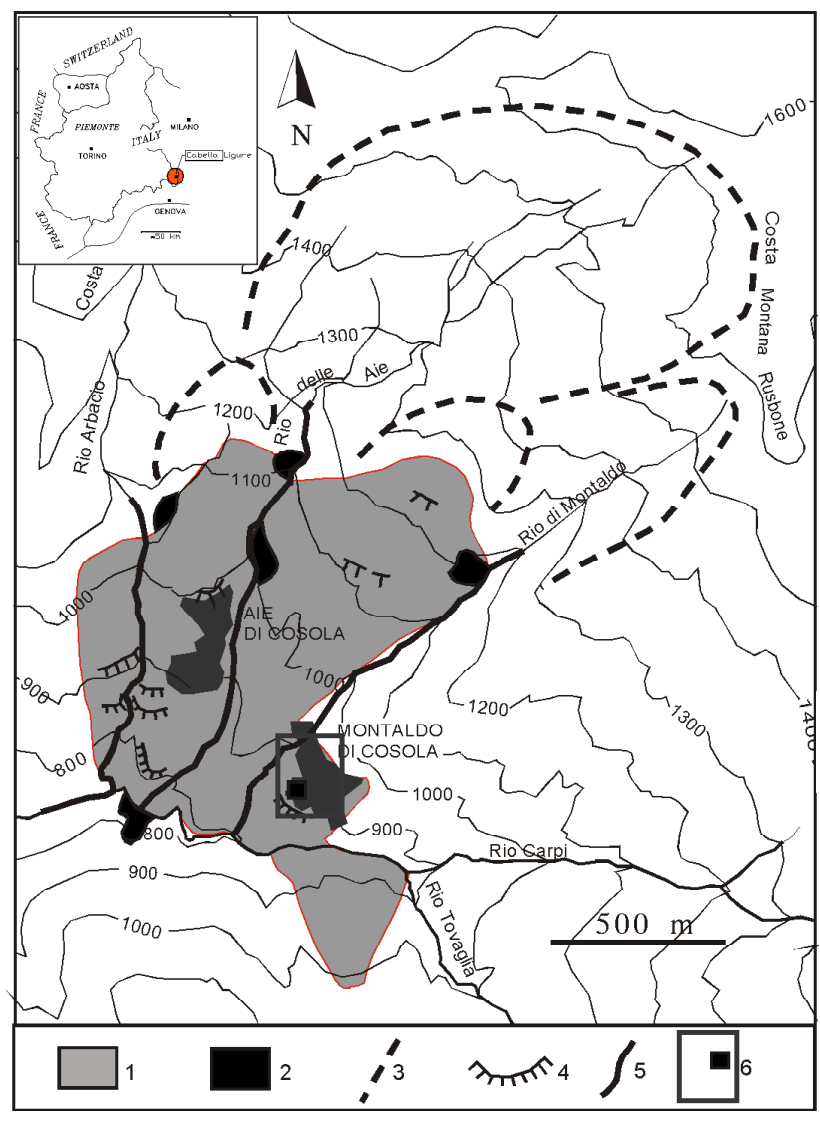

Fig. 1. Sketch map of Montaldo di Cosola landslide. 1) main landslide body; 2) minor, active, rotational slides due to strong stream erosion; 3) eroding areas; 4) main scarps; 5) main landslide crowns; 6) monitored area.

correlation with the rainfalls. In particular it was possible to identify a time lag of about 9 days between the occurrence of a rainfall peak and the corresponding peak in the recorded movements produced by these rainfalls. The existence of a correlation between rainfalls and slope movements had been already qualitatively observed by several authors (Campbell, 1975; Govi and Sorzana, 1980; Caine, 1980; Govi et al., 1985; Zêzere and Rodriguez, 2002; Barton, 2002). Govi et al. (1985), in particular, found a qualitative-general correlation that linked rainfalls and landslide occurrence. Caine (1980), Zêzere and Rodriguez (2002) and many other authors proposed triggering rainfall thresholds. Using the AIS it has been possible to identify, locally, a quantitative and not only qualitative relationship between rainfalls peaks and slope movements peaks.

The time lag of 9 days was more precisely and objectively identified with a cross correlation analysis. The cross correlation function, $\phi_{y x}$, that has been used in the analysis was

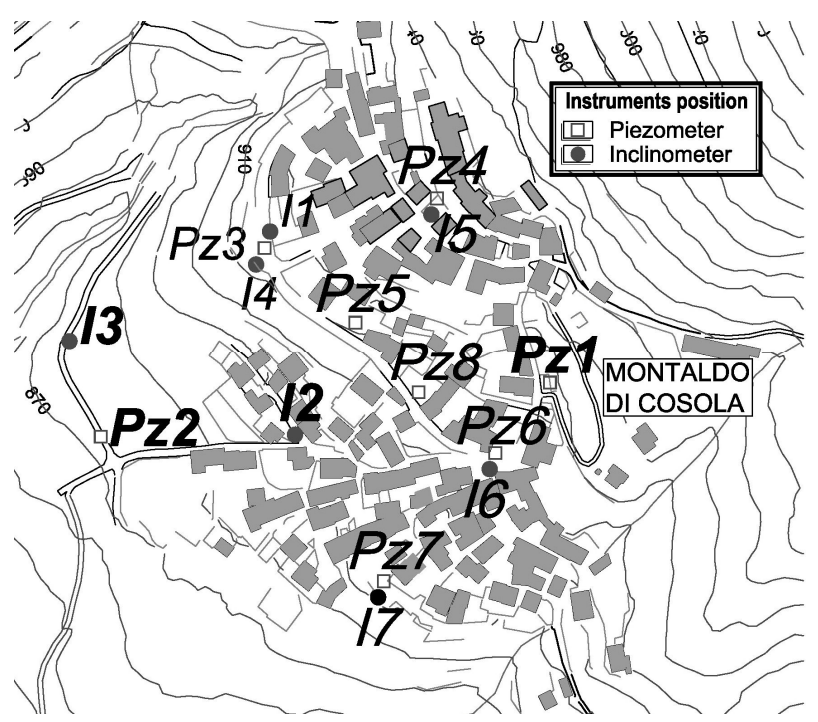

Fig. 2. Sketch map of the monitored area. Inclinometers are labeled with I and piezometers with Pz.

defined as:

$\phi_{y x}(\tau)=\sum_{t=-\infty}^{+\infty} x_{t} y_{t+\tau}$

in which $\mathrm{x}_{t}$ has been assumed as the function expressing the rainfall occurred at the time $\mathrm{t}$ and $\mathrm{y}_{t+\tau}$ as the function expressing the displacements occurred at the depth of about $13 \mathrm{~m}$ at the time $\mathrm{t}+\tau$, calculated for the period 22 September16 March 2000. The cross correlation function, $\phi_{y x}$ presented a maximum for a value of $\tau=9$ days (Lollino et al., 2002). Therefore we could state that the average time of response of the landslide to a rainfall was of 9 days and within that time the landslide would have generally displayed the maximum displacement due to that rainfall (Lollino et al., 2002).

Observations were continued through the years and further analyses of the collected data have become possible. Therefore we have decided to extend the analysis of the correlation between deep slope movements and rainfalls to include a greater period of observation ( 2 more years) to verify over this period the consistency of the time lag mentioned above. The possibility to extend to the entire landslide body the correlation that has been found locally has also been examined, analyzing the results of the remaining inclinometric tubes with traditional reading installed on the landslide and comparing them with the results of the AIS. The output of the piezometers installed on the landslide has also been analysed and the relations existing among rainfalls, ground water level oscillations and the related slope movements have been explored and will be presented in the following. 


\section{Monitoring installations}

The monitoring activities, so far, have been concentrated only on one sector of the landslide (Fig. 1). This sector is close to the hamlet of Montaldo di Cosola and was chosen to provide the citizens with direct information regarding their village and the possible effects of the landslide movements on their houses. The monitoring network consists of five piezometers and six inclinometric tubes, four of which intended for use with a probe inclinometer handled by an operator and the other two provided with an Automated Inclinometer System (AIS).

The inclinometers detected movements along a shallow local surface, located at a depth of $13.5 \mathrm{~m}$, probably connected with a rotational slide along a scarp. As previously mentioned the AIS is an inclinometer apparatus designed to operate by remote control (Lollino, 1992; Lollino et al., 2002). It combines the advantages of the measurements made by an operator with a probe inclinometer and the measurements made by in-place inclinometers (Mikkelsen, 1996; Dunnicliff, 1995), since it allows the possibility of a practically infinite number of reading points with almost continuous recording capabilities. The AIS is run by a central unit microprocessor and allows several automatic measurements which would be too expensive if made by an operator. The composition of the AIS and its main characteristics can be found in Lollino et al., 2002.

\section{Correlation between slope deep movements and rain- falls}

As already mentioned in the introduction, a cross-correlation analysis of the displacement data coming from the AIS and the rainfalls recorded during the same time interval was performed for the period September 2000-March 2001. This analysis revealed that a time lag of 9 days existed between the rainfall peaks and the corresponding peaks in the recorded movements.

Further observations of the same type were carried out for the period May 2002-May 2004 with the purpose of verifying the results previously mentioned over a larger period of time. During such a period the landslide displacements were recorded through the AIS and also the rainfalls were collected. A comparison between the recorded rainfalls and the displacements occurred at the depth of about $13 \mathrm{~m}$ for the period May 2002-May 2004 is shown in Fig. 3.

By analyzing the data shown in this latter figure it is possible to notice that some correlation exists between rainfalls and movements, as it had been observed already for the period September 2000-March 2001. This occurrence had been already observed by several other authors in other sites. Thanks to the AIS that performs daily measurements, it has been possible to recognize that the most significant movements occur with a certain delay after the rainfalls. In partic-

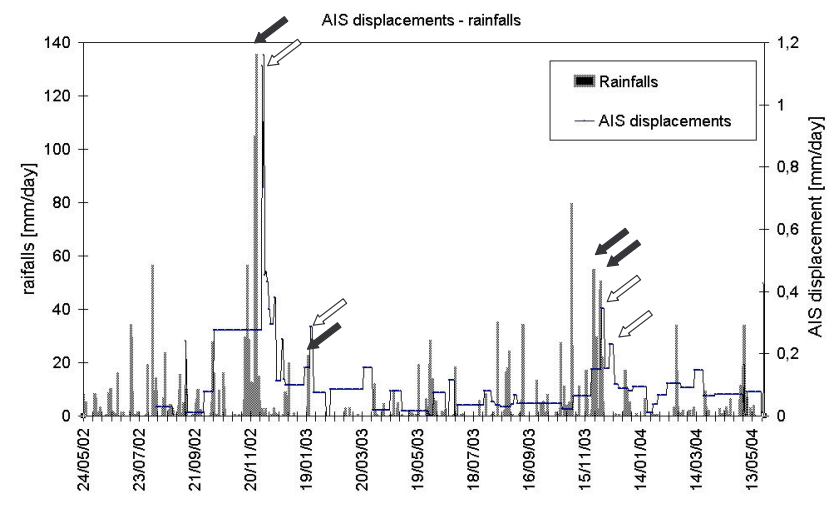

Fig. 3. Comparison between daily rainfalls and daily displacements at the depth of $13.5 \mathrm{~m}$ during the period May 2002-May 2004. The white arrows point out the most significant displacements that were preceded by significant rainfall peaks (black arrows).

ular an evident time lag exists between the occurrence of the most significant rainfall peaks and the corresponding peaks in the recorded movements. However, the amount of this time lag is not easily and immediately identifiable from the graph of Fig. 3. The use of cross-correlation facilitates and makes more objective its identification (Stearns and David, 1996). Thus a cross-correlation analysis of the recorded data has been performed to identify more objectively the time lag and also to verify the consistency of the time lag found for the period 2000-2001. The analysis was performed following the same criteria exposed in the introduction.

It must be noticed, however, that some lack of data is present in the records shown in Fig. 3, as it will appear from the data of Fig. 5 regarding the AIS measurements.

The cross correlation analysis revealed that the time lag between the rainfall peaks and the corresponding peaks in the recorded movements for the period May 2002-May 2004 is of 8 days. Even though Fig. 3 shows that not all the rainfalls peaks are necessarily followed by a peak of displacement, nevertheless several of the most significant rainfall peaks are. These latter are shown with the arrows in Fig. 3. Even though the observation period is quite short, another evidence that seems observable is that the rainfalls that produce significant displacement after 8 days occur in Autumn, which is, as mentioned, the most rainy season of the year. Similar rainfalls occurred during other periods, particularly in Summer, do not seem to produce significant displacements that occur after a predictable delay. For the Summer season this is probably due to the higher evapotranspiration rate that diminishes the soil moisture.

The largest rainfall peak of the period May 2002-May $2004(135.4 \mathrm{~mm})$ occurred in November, in particular on 26 November 2002, exactly like it happened for the data recorded in 2000-2001, when the largest rainfall peak occurred on 6 November 2000. For a comparison with the 2000 precipitation we have calculated the return period of 


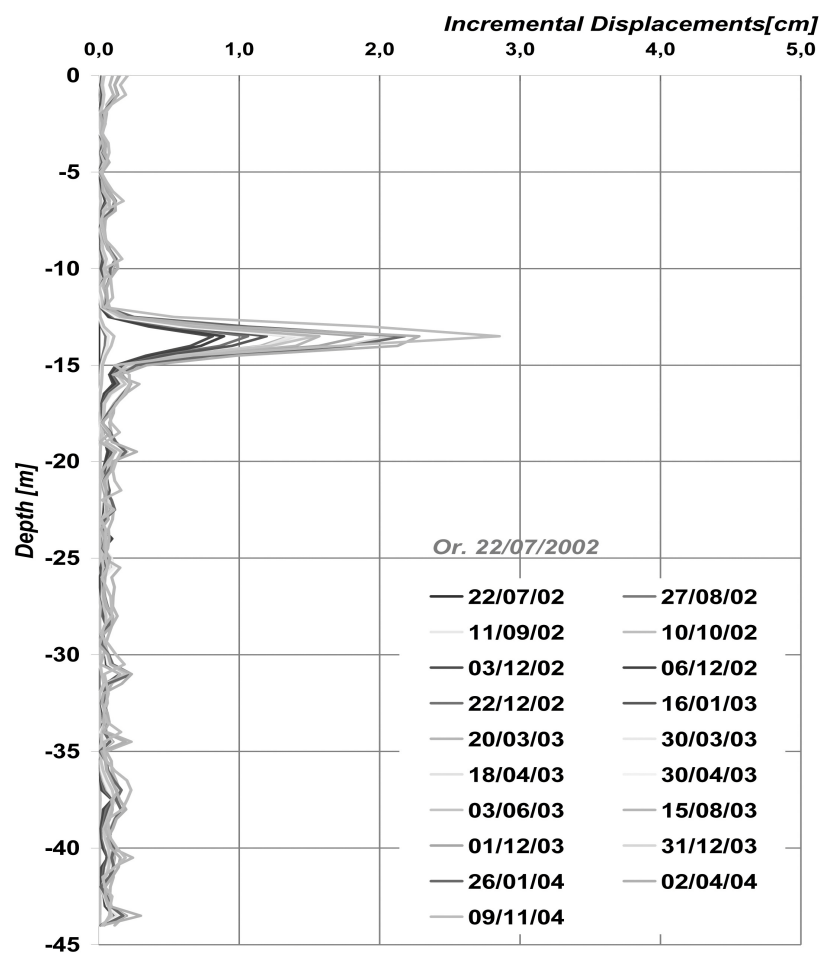

Fig. 4. Resulting displacement as calculated at each point of the borehole where the AIS is installed during the period May 2002May 2004.

the November 2002 rainfalls of 5 consecutive days and this was found to be of 15 years. The 26 November 2002 rainfall peak was followed by a peak in movements (equal to $1.2 \mathrm{~mm} /$ day) 8 days later, that is after a time lag equal to that found through cross correlation.

The effect of the cumulated rainfalls preceding the rainfall peaks producing displacements was also examined. The cross correlation analysis was repeated after having attributed a weight, given by the total amount of rainfalls of the 15 preceding days, to each daily rainfall producing a peak of displacements. No relevant effect was identified and the output of the cross-correlation analysis was the same as before. The rainfalls that precede a rainfall peak that produces a landslide displacement do not seem to have any particular effect on the time lag between rainfalls and displacements. However, it can be noticed that both for the displacements occurred in Autumn 2002 and in Autumn 2003 the rainfalls that produced them were preceded by several rainy days. As previously mentioned this is a common occurrence: October and November are the most rainy months of the year and this is an evident cause of the greater landslide displacements that occur in that period. It is also possible to find in the graph minor displacements that were not preceded by any significant rainfall.

The time lag found has to be considered as a "warning time" for this particular landslide. It means that after a sig-

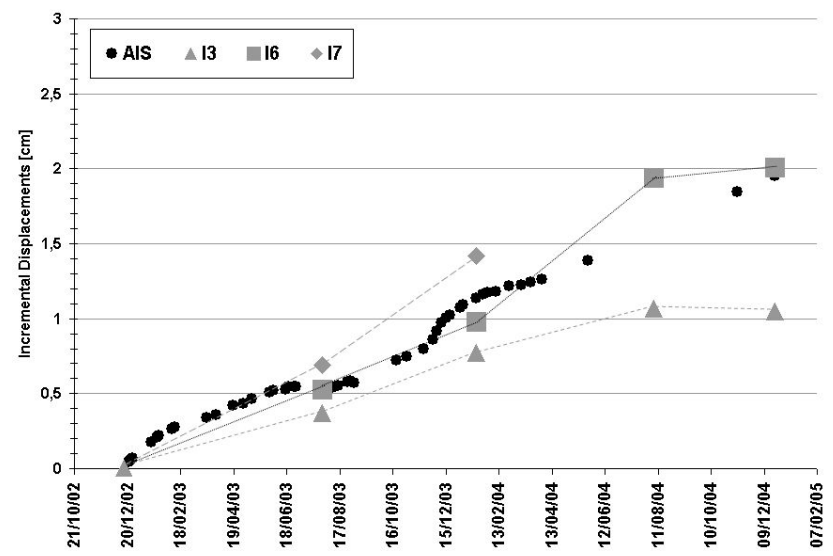

Fig. 5. Displacements measured through the inclinometers I3, I6 and I7 during the period May 2002-May 2004 compared with the measurements performed through the AIS during the same period.

nificant rainfall has taken place, particularly in Autumn, a peak in landslide movements has to be expected around 8-9 days later. As a consequence, fissures in houses, for instance, have to be expected to show their maximum enlargement $8-9$ days after a significant rainfall peak. The population might be warned accordingly.

There is a precise reason for the time lag that has been found. As we will see in a following chapter, the water table fluctuations in response to a certain rainfall are almost immediate and thus an almost immediate response of the landslide should be expected. However, as mentioned earlier, the AIS allowed to locate the sliding surface at a depth of about $13 \mathrm{~m}$ at the level of a sandy-silty layer with some clay lenses inside. The existence and the location of this sliding surface was confirmed by the further measurements performed in the period 2002-2004 (Fig. 4). The presence of silt and clay on the sliding surface explains the time lag, since the low permeability of these materials requires some time for them to reach a level of saturation that allows the movements to start. Therefore each landslide has to be thoroughly investigated in order to use this method for predicting displacement peaks. Each landslide might react differently, according to its particular geological and stratigraphical conditions.

\section{Results of traditional inclinometric measurements}

As previously mentioned and shown in Fig. 2, several other inclinometric tubes with traditional reading have been installed on the landslide body. The results of the measurements performed in these tubes were compared with the data coming from the AIS. In Fig. 5 the comparison is shown.

The results coming from the other inclinometers appear to be coherent with those of AIS. The inclinometer labeled I6 shows practically the same movements recorded by the AIS, as far as the measurements performed in the same days 


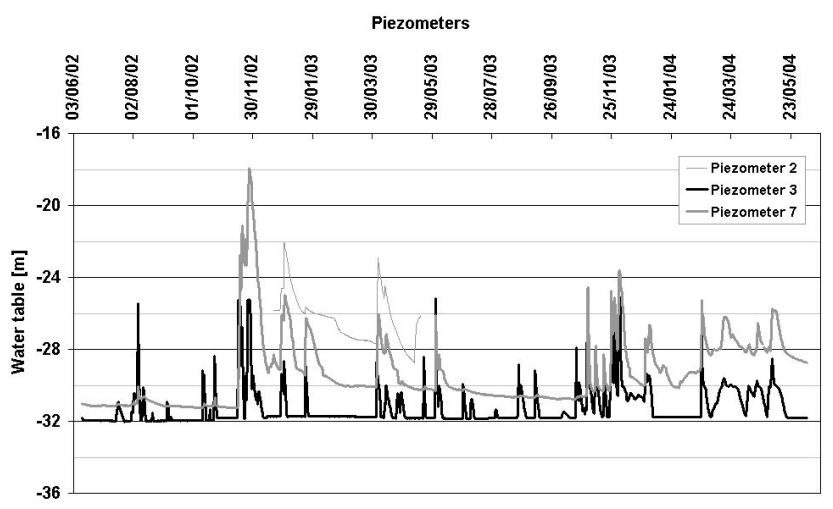

Fig. 6. Ground water level oscillations as measured by piezometers no. 2, 3 and 7 during the period May 2002-May 2004.

are concerned. This inclinometer is located at $949.6 \mathrm{~m}$ a.s.1. along the same road where the AIS (958.2 $\mathrm{m}$ a.s.1.) is located. The inclinometer I3 (located at $917 \mathrm{~m}$ a.s.l.), which is located downslope, has recorded smaller displacements but the trend of these latter is the same of the previous inclinometer and of the AIS. Inclinometer I7 (located at $936.9 \mathrm{~m}$ a.s.1.) has recorded a smaller number of measurements: the trend is similar, but shows greater displacements.

These results show a uniform behavior of the entire landslide. This should allow to assume that the findings performed at a single point through the AIS can be extended to the entire landslide body. The entire landslide is thus expected to show a peak of displacement when 8-9 days have elapsed after a significant rainfall peak.

\section{Ground water level oscillations}

In Fig. 6 the ground water level oscillations as measured by piezometers no. 2, 3 and 7 are shown. In Fig. 7 the ground water level oscillations as measured by piezometer no. 3 are compared with the rainfalls.

The three piezometers respond contemporaneously to the rainfalls (piezometer 2 has stopped its recordings on October 2003), even though the amounts of the oscillations are different because of their different locations.

The response of the ground water level to the rainfalls appears to be very rapid, as it can be observed in Fig. 7 .

As previously mentioned, a time lag of 8-9 days takes place between rainfall peaks and displacement peaks, even though the response of the ground water level to the rainfalls is so rapid, because of the presence of silt and clay at the level of the sliding surface located $13 \mathrm{~m}$ below the ground level. The very low permeability of these materials requires evidently several days before a level of saturation is reached that allows the inception of the movements.

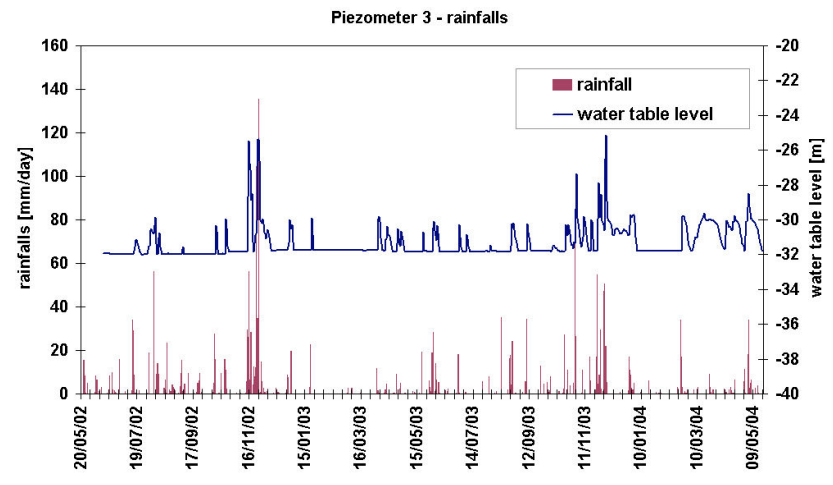

Fig. 7. Ground water level oscillations as measured by piezometer no. 3 compared with the rainfalls recorded during the period May 2002-May 2004.

\section{Conclusions}

A complex monitoring network has been installed on a landslide located in North-Western Italy, on the Apennines Mountains. An Automatic Inclinometric System (AIS) has allowed to identify, through a cross correlation analysis, a recurrent time lag of 8-9 days between the occurrence of significant rainfall peaks and the corresponding peaks of the landslide displacements. Therefore the prediction of a possible moment of crisis of the landslide has become possible: fissures in houses, for instance, have to be expected to show their maximum enlargement $8-9$ days after a significant rainfall peak and the population might be warned accordingly. Other useful applications and advantages of these findings could be certainly found. A great advantage is certainly given by the sense of security and confidence deriving from the possibility of predicting when the most important consequences of a landslide movement is expected. The time lag will not necessarily remain the same through the years; however, continuing the monitoring activity, it will be possible to identify possible changes. As far as warning purposes are concerned, the AIS would need to be maintained in place continuously and its data to be systematically processed by experts in order to maintain its workability up-to-date. Each landslide has to be thoroughly investigated in order to use this method for predicting displacement peaks. Each landslide might in fact react differently, according to its particular geological and stratigraphical conditions.

The AIS was already known as a tool to design more reliable warning systems since it allows to schedule the measurement recurrences, to increase the reading levels and their precision and to measure speed and acceleration of the possible movements (Lollino, 1992; Lollino et al., 2002). The experience described in this paper has shown that if a correspondence between rainfall peaks and displacements at the depth of the sliding surface exists, the prediction of a possible moment of crisis for an active landslide could be also possible some time in advance, with the use of the AIS. 
This has certainly further increased the performance of the AIS as a warning system besides its use as a monitoring device.

Edited by: L. Marchi

Reviewed by: A. Pasuto and M. Mikos

\section{References}

Barton, M. E.: Early warning of landsliding using weather station data, Instability - Planning and Management, Thomas Telford, London, 455-462, 2002.

Caine, N.: The rainfall intensity-duration control of shallow landslides and debris flows, Geografiska Annaler, 62A, 1-2, 23-27, 1980.

Campbell, R. H.: Soil slip, debris flows and rainstorms in the Santa Monica Mountains and Vicinity, Southern California, U.S. Geological Survey Professional Paper, 851, 1975.

Dunnicliff, J.: Geotechnical Instrumentation for Monitoring Field Performance, John Wiley \& Sons, New York, 1988.

Dunnicliff, J.: Monitoring and instrumentation of landslides, Proceedings of the 6th International Symposium on Landslides, Christchurch, New Zealand, 10-14 February 1992, A. A. Balkema, Rotterdam, 1881-1895, 1995.
Govi, M., Mortara, G., and Sorzana, P. F.: Eventi idrologici e frane, Geologia Applicata ed Idrogeologia, XX, Part II, 359-375, 1985.

Govi, M. and Sorzana, P. F.: Landslide Susceptibility as a function of critical rainfall amount in Piedmont basin (North Western Italy), Studia Geomorphologica Carpatho-Balcanica, 14, 43-61, 1980.

Lollino, G.: Automated Inclinometric system, Proceedings of the 6th International Symposium on Landslides, Christchurch, New Zealand, 10-14 February 1992, A. A. Balkema, Rotterdam, 1147-1150, 1992.

Lollino, G., Arattano, M., and Cuccureddu, M.: The use of the Automatic Inclinometric System (AIS) for landslide early warning: the case of Cabella Ligure (North -Western Italy), Phys. Chem. Earth, 27, 36, Elsevier Science Ltd., 1545-1550, 2002.

Mikkelsen, P. E.: Field instrumentation, in: Landslides, investigation and mitigation, edited by: Turner, A. K. and Schuster, R. L., Transportation Research Board National Research Council, National Special report 247, Academy Press, Washington D.C., 278-316, 1996.

Stearns, S. D. and David, R. A.: Signal processing algorithms in Matlab, Prentice Hall P. T. R., Upper Saddle River, New Jersey, 1996.

Zêzere, J. L. and Rodriguez, M. L.: Rainfall thresholds for landsliding in Lisbon Area (Portugal), Landslides, Proceedings of the First European conference on Landslides, Prague, Czech Republic, 24-26 June, A. A. Balkema, 333-338, 2002. 